\title{
Real-life data of major and minor bleeding events with direct oral anticoagulants in the one-year follow-up period: The NOAC-TURK study
}

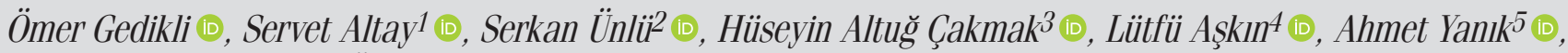

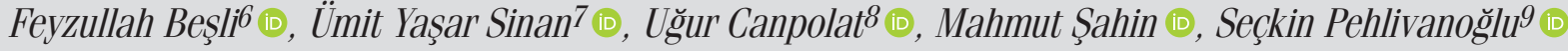 \\ Department of Cardiology, Faculty of Medicine, Ondokuz Mayıs University; Samsun-Turkey \\ ${ }^{1}$ Department of Cardiology, Faculty of Medicine, Trakya University; Edirne-Turkey \\ ${ }^{2}$ Department of Cardiology, Faculty of Medicine, Gazi University, Ankara-Turkey \\ ${ }^{3}$ Department of Cardiology, Mustafa Kemal Paşa State Hospital, Bursa-Turkey \\ ${ }^{4}$ Department of Cardiology, Faculty of Medicine, Adıyaman University; Adıyaman-Turkey \\ ${ }^{5}$ Department of Cardiology, Samsun Education and Research Hospital; Samsun-Turkey \\ ${ }^{6}$ Department of Cardiology, Faculty of Medicine, Harran University; Şanlıurfa-Turkey \\ ${ }^{7}$ Institute of Cardiology, Faculty of Medicine, İstanbul University; İstanbul-Turkey \\ ${ }^{8}$ Department of Cardiology, Faculty of Medicine, Hacettepe University, Ankara-Turkey \\ ${ }^{9}$ Department of Cardiology, Faculty of Medicine, Başkent University, İstanbul-Turkey
}

\section{ABSTRACT}

Objective: This study aimed to evaluate the safety of direct oral anticoagulants (DOACs) in patients with non-valvular atrial fibrillation (NVAF) during daily clinical practice.

Methods: This was a prospective study conducted between January 01, 2016, and April 01, 2017, in patients aged $\geq 18$ years with a diagnosis of NVAF. We performed the study in 9 clinical centers from different regions of Turkey, and the mean follow-up period was $12+2$ months. We investigated major and minor bleeding events of DOAC.

Results: A total of 1807 patients with NVAF were enrolled. The mean age of the patients was $73.6 \pm 10.2$ years, CHA2DS2-VASc score was $3.6 \pm 1.4$, and HAS-BLED score was $2 \pm 1.2$. The most frequently prescribed DOAC was dabigatran $110 \mathrm{mg}$ bid in $409(22.6 \%)$ patients. The patients on apixaban $2.5 \mathrm{mg}$ bid were older $(\mathrm{p}<0.001)$. Patients on rivaroxaban $15 \mathrm{mg}$ od also had a higher prevalence of chronic renal failure, $46(16.7 \%)$ patients. A total of $205(11.4 \%)$ bleeding events were observed; among these, $34(1.9 \%)$ patients had major bleeding and $171(9.4 \%)$ patients had minor bleeding. The major and minor bleeding events were $2 / 273(0.7 \%)$ and $30 / 273(10.9 \%)$ in patients receiving dabigatran 150 $\mathrm{mg}$ bid, $13 / 409(3 \%)$ and $44 / 409(10.7 \%)$ in patients receiving dabigatran $110 \mathrm{mg}$ bid, $4 / 385(1 \%)$ and $42 / 385(10.9 \%)$ in patients receiving rivaroxaban $20 \mathrm{mg}$ od, $8 / 276(2.9 \%)$ and $27 / 276(9.7 \%)$ in patients receiving rivaroxaban $15 \mathrm{mg}$ od, $3 / 308(0.9 \%)$ and $14 / 308(4.5 \%)$ in patients receiving apixaban $5 \mathrm{mg}$ bid, 4/156 (2.5\%) and 14/156 (9\%) in patients receiving apixaban $2.5 \mathrm{mg}$ bid, respectively. The total bleeding events were $17(5.6 \%)$ in patients receiving apixaban $5 \mathrm{mg}$, less than those receiving other DOACs. On multivariate analyses, rivaroxaban $20 \mathrm{mg}$ od $(\mathrm{p}=0.002)$, ATRIA and HAS-BLED scores, and peripheral artery disease were independent indicators of bleeding. The most frequent location of major bleeding was the gastrointestinal system (GIS) [17 (0.9\%) patients], and the most frequent location of minor bleeding was the gingiva [45 (2.5\%) patients].

Conclusion: This study showed that similar results as the previous real-life study; however, we had some different results, such as the GIS tract bleeding was more frequent in patients receiving dabigatran $110 \mathrm{mg}$ bid. The major and intracranial bleeding events were similar for different DOACs; and among DOACs, only rivaroxaban $20 \mathrm{mg}$ od was associated with a high risk of bleeding.

Key words: direct oral anticoagulants, major bleeding, minor bleeding, real-life data, non-valvular atrial fibrillation

Cite this article as: Gedikli Ö, Altay S, Ünlü S, Çakmak HA, Aşkın L, Yanık A, et al. Real-life data of major and minor bleeding events with direct oral anticoagulants in the one-year follow-up period: The NOAC-TURK study. Anatol J Cardiol 2021; 25: 196-204.

Address for Correspondence: Dr. Ömer Gedikli, Ondokuz Mayıs Üniversitesi Tıp Fakültesi,

Kardiyoloji Anabilim Dalı, Samsun-Türkiye

Phone: +90 362312 1919-2411 E-mail: drgedikli@hotmail.com

Accepted Date: 08.01.2021 Available Online Date: 22.02.2021

(C) Copyright 2021 by Turkish Society of Cardiology - Available online at www.anatoljcardiol.com DOI:10.5152/AnatolJCardiol.2021.57635 


\section{HIGHLIGHTS}

- A total of $205(11.4 \%)$ bleeding events were observed in patients on direct oral anticoagulants (DOACs).

- Rivaroxaban $20 \mathrm{mg}$ once daily was an independent indicator of bleeding.

- Reduced dosage of DOACs is associated with higher bleeding rates.

- Peripheral artery disease was associated with bleeding in this study.

- Major and intracranial bleeding events were similar for different DOACs.

\section{Introduction}

Atrial fibrillation (AF) is the most common arrhythmia diagnosed in clinical practice (1). Anticoagulation is the essential therapy for the management of $A F$, and anticoagulation treatment strategy should be applied according to CHA2DS2-VASc scoring system in patients with non-valvular AF (NVAF) (2). The effectiveness and safety of direct oral anticoagulants (DOACs) have been proved in previous studies; nevertheless, bleeding is a serious and common side effect of DOACs (3-5). DOACs may cause bleeding, which can vary from minor bleeding to major bleeding or life-threatening intracranial hemorrhages (3-7). The new oral anticoagulants-Turkey (NOAC-TURK) study has reported bleeding and ischemic events in patients using DOACs in Turkey (8). Despite having a retrospective analysis of the association between bleeding risk and DOAC-related events (9-11), no prospective study with at least 1-year follow-up of real-life data has been conducted yet. Therefore, this study aimed to investigate the major and minor bleeding event rates, sites, and management in patients with the indication of NVAF treated with DOACs.

\section{Methods}

This study was designed by the young cardiologists of Turkey with an aim to prospectively investigate DOAC-related bleeding events in a 1-year follow-up of patients with NVAF who participated in the NOAC-TURK study. The DOAC regimen and treatment duration differ for NVAF, deep venous thrombosis (DVT), and pulmonary thromboembolism (PTE) (12). A total of 1,807 patients from 9 centers were followed prospectively. The number of participants was less than those in the NOAC-TURK study. A total of 10 centers did not participate in the follow-up study owing to the change in the clinic center and the position of the investigator, 20 patients were lost to follow-up, and the patients receiving DOACs with indications of DVT and PTE were excluded.

The study was conducted between January 01, 2016, and April 01, 2017. Patients older than 18 years with a diagnosis of NVAF and indication for DOACs were included. Any contraindi- cation to the usage of DOAC was accepted as exclusion criteria. The follow-up of the patients was performed face to face or via a telephone interview. Any history of hypertension, chronic kidney disease, coronary artery disease (history of percutaneous intervention or coronary artery bypass graft surgery), peripheral artery disease (PAD), diabetes mellitus, congestive heart failure, and valvular disorders (any degree of mitral regurgitation, aortic stenosis, or aortic regurgitation) were recorded. Demographic, clinical, and laboratory characteristics of the study participants were obtained via the NOAC-TURK survey database. If available, new clinical and laboratory parameters were added to the database. Medical records required for the study were obtained from the participating centers via electronic file transfers. The medical records included the occurrence of new clinical events or diagnoses, such as stroke and other embolic adverse events, coronary heart disease, hypertension, diabetes mellitus, congestive heart failure, and vascular disease (prior myocardial infarction, PAD). CHA2DS2-VASc, HAS-BLED, and ATRIA scores of patients were re-calculated (13-15). Modification of diet in renal disease (16) was used for calculating the glomerular filtration rate (GFR). Chronic renal failure (CRF) was defined as having a GFR $<60 \mathrm{~mL} / \mathrm{min}$. Major bleeding was defined as a decrease in the hemoglobin level of at least $2 \mathrm{~g} / \mathrm{dL}$ or requiring 2or more units of whole blood/erythrocyte transfusion or symptomatic bleeding in a critical organ/ area according to the international society on thrombosis and hemostasis criteria (17). Minor bleeding was characterized as any sign or symptom of hemorrhage and clinically relevant bleeding without major bleeding that was considered to be related to DOACs use. Symptomatic and clinically relevant gingival bleeding was considered in this study. Temporary discontinuation was defined as an interruption of DOACs for shorter than 4 weeks without the initial plan.

The Local Ethics Committee approval was obtained (the Ethics Committee of Haydarpaşa Numune Training and Research Hospital; HNEAH-KAEK 2015/KK/60). Informed consent was obtained from all participants.

\section{Statistical analysis}

Continuous variables were presented as mean \pm standard deviation, and categorical data were presented as percentages or frequencies. Continuous variables were examined by the Kolmogorov-Smirnov test to check for normality of distribution. Categorical variables were compared by the $\chi^{2}$ test.

The patient population was categorized on the basis of the type of DOAC and bleeding status. Baseline characteristics were compared among groups using the Student's t-test or oneway analysis of variance (ANOVA) test. Significant determinants of bleeding were determined via the Cox proportional hazard model with a backward stepwise likelihood ratio. Clinical variables, including age, sex, type of DOAC, and CHA2DS2-VASc, HAS-BLED, ATRIA scores were analyzed in a multivariable model. Sex, type of DOAC, and having comorbidities were encoded as categorical variables, and the remaining were encoded as continuous variables. The significance level for a 


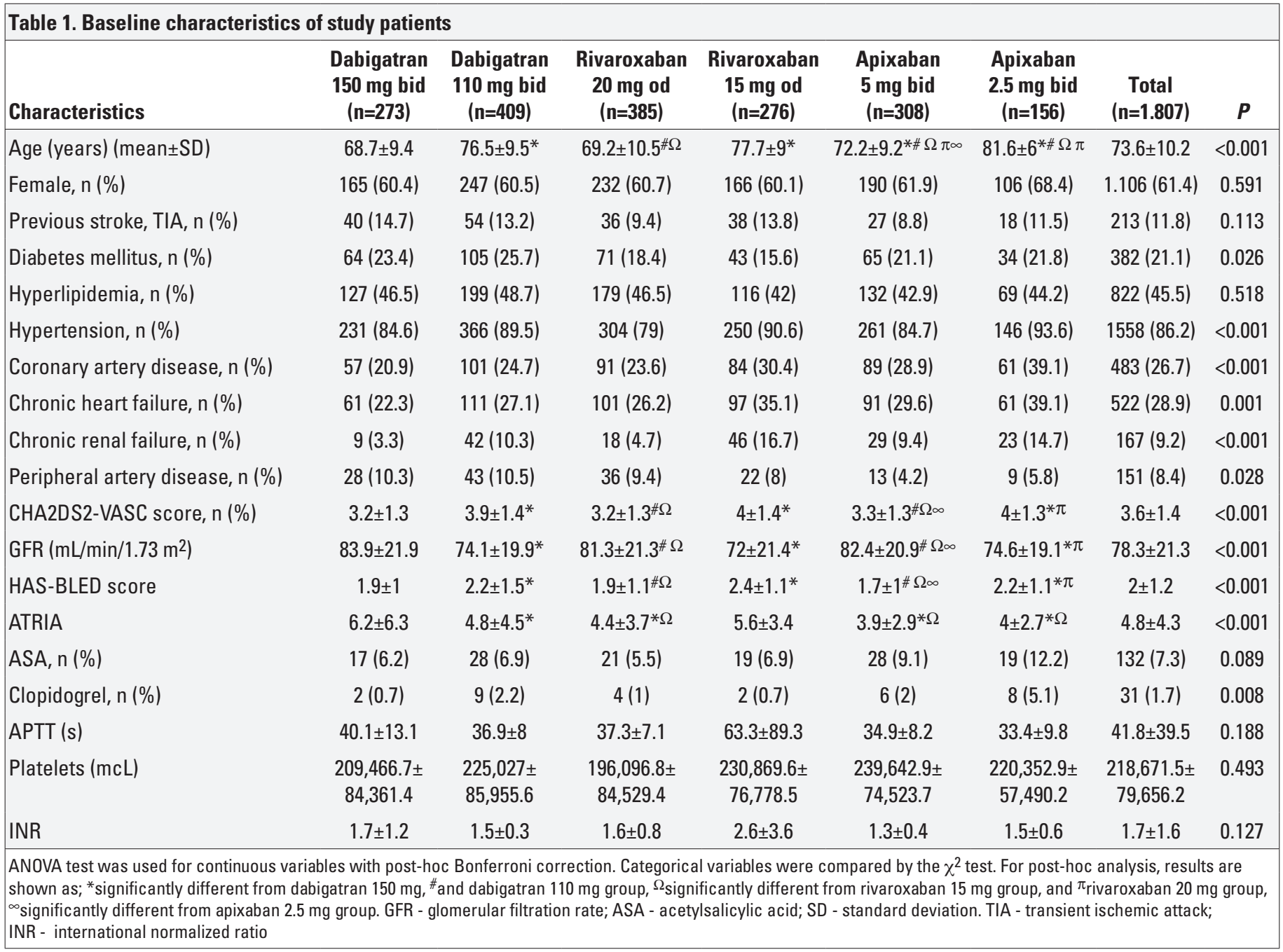

variable to remain in the multivariable model was 0.05 , and the exclusion criterion was 0.10 . A two-tailed $p$-value of $<0.05$ was considered statistically significant. All the data were analyzed using the Statistical Package for Social Sciences version 23.0.

\section{Results}

A total of 1,807 patients with NVAF were enrolled. Demographic characteristics of the study population are presented in Table 1. Of the patients, $409(22.6 \%)$ were prescribed dabigatran $110 \mathrm{mg}$ bid, which was the most frequently prescribed DOAC; followed by rivaroxaban $20 \mathrm{mg}$ od, which was prescribed to $385(21.3 \%)$ patients; and apixaban $5 \mathrm{mg}$ prescribed to $308(17 \%)$ patients. Patients who were on dabigatran $150 \mathrm{mg}$ and rivaroxaban $20 \mathrm{mg}$ od therapies were younger $(p<0.001$, ANOVA) with better glomerular filtration rate and CHA2DS2-VASc and HAS-BLED scores (all $p<0.001$, ANOVA). The patients on apixaban $2.5 \mathrm{mg}$ bid therapy had the highest mean age compared with other groups ( $p<0.001$, ANOVA). Moreover, they had a more common prevalence of coronary artery disease [61 (39.1\%) patients] and chronic renal disease [23 $(14.7 \%)$ patients]. Patients on rivaroxaban $15 \mathrm{mg}$ od also had a higher prevalence of chronic renal disease [46 (16.7\%) patients].

In this study, 205 (11.4\%) bleeding events were observed; among these, $34(1.9 \%)$ patients had major bleeding and 171 $(9.4 \%)$ patients had minor bleeding. The major and minor bleeding events were $2 / 273(0.7 \%)$ and $30 / 273(10.9 \%)$ on dabigatran $150 \mathrm{mg}$ bid, $13 / 409(3 \%)$ and $44 / 409(10.7 \%)$ on dabigatran $110 \mathrm{mg}$ bid, $4 / 385$ (1\%) and 42/385 (10.9\%) in rivaroxaban $20 \mathrm{mg} \mathrm{od}, 8 / 276$ $(2.9 \%)$ and $27 / 276(9.7 \%)$ on rivaroxaban $15 \mathrm{mg} \mathrm{od}, 3 / 308(0.9 \%)$ and $14 / 308(4.5 \%)$ in apixaban $5 \mathrm{mg}$ bid, and 4/156 (2.5\%) and $14 / 156(9 \%)$ in apixaban $2.5 \mathrm{mg}$ bid, respectively (Table 2).

Baseline demographic and clinical characteristics according to having a bleeding event are presented in Table 3. Patients who experienced a bleeding event were older and had higher CHA2DS2-VASC, HAS-BLED, and ATRIA scores along with hyperlipidemia, PAD, and lower GFR (all $p<0.001$, ANOVA). The multiple Cox regression analyses are presented in Table 4 and reveals that rivaroxaban $20 \mathrm{mg}$ od [hazard ratio $(\mathrm{HR})=1.760,95 \%$ confidence interval (CI): $1.228-2.524, p=0.002]$ is independently associated with bleeding among DOAC groups. The other significant independent parameters associated with bleeding were found to be high ATRIA and HAS-BLED scores and having PAD (Table 4). 


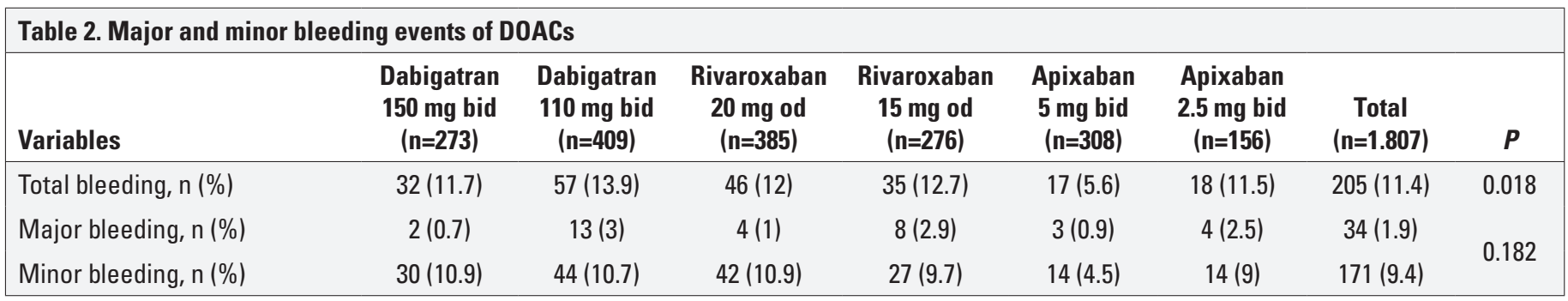

\begin{tabular}{|c|c|c|c|}
\hline Characteristic & $\begin{array}{l}\text { Patients without } \\
\text { bleeding } \\
\text { ( } \mathrm{n}=1.602 \text { ) }\end{array}$ & $\begin{array}{l}\text { Patients with } \\
\text { bleeding } \\
\text { (n=205) }\end{array}$ & $\boldsymbol{P}$ \\
\hline Age (years) (mean $\pm S D)$ & $73.3 \pm 10.2$ & $76.6 \pm 10.2$ & $<0.001$ \\
\hline Female, n (\%) & $983(61.1)$ & $130(63.4)$ & 0.290 \\
\hline Previous stroke TIA, n (\%) & $186(11.5)$ & $31(15)$ & 0.170 \\
\hline Diabetes mellitus, $\mathrm{n}(\%)$ & $341(21)$ & $47(22.7)$ & 0.528 \\
\hline Hyperlipidemia, n (\%) & $712(44)$ & $122(58.9)$ & $<0.001$ \\
\hline Hypertension, n (\%) & $1399(86.4)$ & $178(86)$ & 0.914 \\
\hline $\begin{array}{l}\text { Coronary artery disease, } \\
\mathrm{n}(\%)\end{array}$ & $421(26)$ & $66(31.9)$ & 0.079 \\
\hline Chronic heart failure, $\mathrm{n}(\%)$ & $468(28.9)$ & $56(27.1)$ & 0.625 \\
\hline Chronic renal failure, $\mathrm{n}(\%)$ & $140(8.6)$ & $29(14)$ & 0.015 \\
\hline $\begin{array}{l}\text { Peripheral artery disease, } \\
\mathrm{n}(\%)\end{array}$ & $124(7.7)$ & $30(14.5)$ & 0.001 \\
\hline CHA2DS2-VASC score & $3.5 \pm 1.4$ & $4 \pm 1.5$ & $<0.001$ \\
\hline GFR, mL/min/1.73 m² & $79.1 \pm 21$ & $70.9 \pm 22.6$ & $<0.001$ \\
\hline HAS-BLED score & $2 \pm 1$ & $2.5 \pm 1.1$ & $<0.001$ \\
\hline ATRIA & $4.6 \pm 4.2$ & $6.6 \pm 4.7$ & $<0.001$ \\
\hline ASA, $n(\%)$ & $114(7)$ & $19(9.2)$ & 0.164 \\
\hline Clopidogrel, n (\%) & $29(1.8)$ & $2(1)$ & 0.300 \\
\hline
\end{tabular}

Student $t$-test was used to compare groups according to bleeding status. GFR glomerular filtration rate; ASA - acetylsalicylic acid; TIA - transient ischemic attack

The sites of major and minor bleeding and management of bleeding events are summarized in Table 3 . There was a significant difference in the rates of total bleeding and major gastrointestinal system (GIS) bleeding among DOAC groups with them being higher for dabigatran $110 \mathrm{mg}$. Patients [17 $(5.6 \%)]$ receiving apixaban $5 \mathrm{mg}$ bid therapy had the lowest rates for bleeding events. Intracranial bleeding was observed in $6(0.3 \%)$ patients ( 2 patients on dabigatran $110 \mathrm{mg}$ bid, 2 on rivaroxaban $15 \mathrm{mg}$ od, 1 on apixaban $2.5 \mathrm{mg}$ bid, and 1 on apixaban $5 \mathrm{mg}$ bid). No difference was observed for the rates of intracranial bleeding events among the DOAC groups (Table 5). A total of $140(68.3 \%)$ patients required medical and surgical intervention, and $91(44.4 \%)$ patients were hospitalized. The rates of temporary discontinuation and changes in anticoagulant therapy were $113(55.1 \%)$ and $75(36.6 \%)$ patients, respectively. A total of $12(66.7 \%)$ patients were hospitalized among those receiving apixaban $2.65 \mathrm{mg}$ bid. There was no significant difference among DOACs.

\section{Sites of major bleeding}

Our data showed that the most frequent location of major bleeding was the GIS in $17(0.9 \%)$ patients, followed by intracranial bleeding in $6(0.3 \%)$ patients. The other types of bleeding that were observed were hematuria in $4(0.2 \%)$, epistaxis and bruising/ecchymosis in $3(0.2 \%)$, and intramuscular in $1(0.1 \%)$.

\section{Sites of minor bleeding}

In our study, the most frequent location of minor bleeding was the gingiva in $45(2.5 \%)$ patients, followed by the GIS in 40 $(2.2 \%)$ patients, and genitourinary system [hematuria in $23(1.3 \%)$ patients]. Other types of minor bleeding were epistaxis in 21 $(1.2 \%)$ patients and conjunctiva in $15(0.8 \%)$ patients.

\section{Management of bleeding}

A total of 91 (44.4\%) patients who experienced any type of bleeding were hospitalized. The medical or surgical therapies and interventions used for the management of bleeding were similar among the DOAC groups (Table 3). The anticoagulation therapy was changed for $75(36.6 \%)$ patients, and the drug was temporarily discontinued in $113(55.1 \%)$ patients; these rates were similar among the NOAC groups.

\section{Discussion}

Our study was the first multicentric 1-year prospective follow-up study in a large cohort of patients on DOAC treatment with the diagnosis of NVAF from different regions of Turkey. Because they were released into the market earlier, dabigatran $110 \mathrm{mg}$ bid was the most prescribed DOAC, followed by rivaroxaban $20 \mathrm{mg}$ od, and apixaban $5 \mathrm{mg}$ bid. However, edoxaban was introduced to the DOAC market after this study and therefore was not included.

The demographic characteristics of our patients were similar to those of other studies $(3-5,7,18-21)$. However, there was less CRF, higher GFR, and a higher rate of female patients regardless of the DOAC type. The average CHA2DS2-VASc score was similar to the RAMSES (9), AFTER (10), and NOAC-TR (11) studies. We also observed that low-dose DOAC was used in the treatment of patients with high CHA2DS2-VASc score, similar to a nationwide cohort study (19).

In this study, the total bleeding rate was $11.4 \%$, higher than the first NOAC-TURK study findings of $217(7.6 \%)$ patients. The 


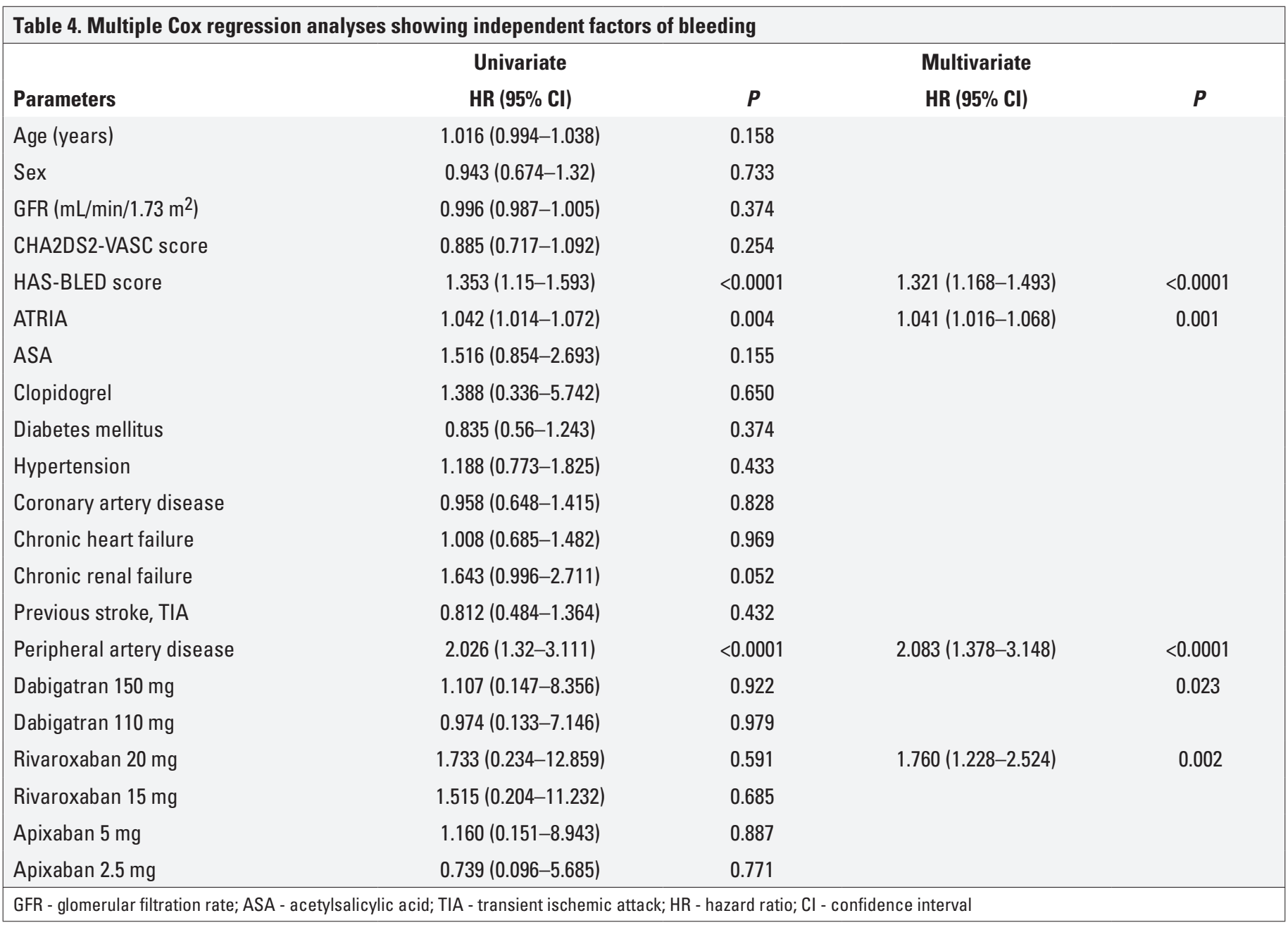

EORP-AF study (22) had similar results with our study as they reported the bleeding event rate at $8.4 \%$ and $11 \%$ for the first and second-year follow-up, respectively. In the literature, the annual rate of total bleeding and major bleeding in patients receiving DOAC treatment was reported to be $4.5 \%-5.4 \%$ and $2.1 \%-3.6 \%$, respectively. For apixaban users, the rate of any bleeding event can rise to $18.1 \%$ per year (17).

In this study, the patients receiving DOAC had fewer bleeding events than those reported in the literature. This difference could be related to a shorter follow-up period (12+2 months). Furthermore, patients receiving lower dosage forms of DOACs had a higher incidence of bleeding events. This finding might be explained by impaired renal function $(74.6 \pm 19.1 \mathrm{~mL} / \mathrm{min})$ and increased age (81.6 \pm 6 years). Patients taking apixaban $(5 \mathrm{mg})$ bid had less major and non-major bleeding. The ARISTOTLE trial showed that minor bleeding was more common than major bleeding and occurred less frequently with apixaban than warfarin. In pilot trials, such as RE-LY and ARISTOTLE, minor bleeding was not the primary endpoint for safety $(3,5)$. Our data demonstrated that similar results for minor bleeding events but not for major bleeding events. Minor bleeding is clinically important because it is a common complication and often results in adverse consequences, including hospitalization and discontin- uation or changes in effective anticoagulation that may lead to worse clinical outcomes. Helmert et al. (23) found in the Dresden study that the major bleeding rate was $2.8 / 100$ patient-years and was significantly higher in patients receiving the $2.5 \mathrm{mg}$ bid dose than those receiving the $5 \mathrm{mg}$ bid dose (5.3 versus 2.2/100 patient-years) for apixaban. In our study, the bleeding events occurred more often with apixaban $2.5 \mathrm{mg}$ bid than for apixaban $5 \mathrm{mg}$ bid. However, the rate of bleeding was less than that of the Dresden study.

Furthermore, the population in the Dresden study was older (median age: 74 versus 72 years for apixaban $5 \mathrm{mg}$ and 83 versus 81years for apixaban $2.5 \mathrm{mg}$ ), the follow-up period was more extended (median: 33 versus 12 months), and the number of patients with renal failure was less in our study for apixaban 2.5 mg $(26.4 \%$ versus $14.7 \%)$ (23). In addition, Emren et al. (11) reported that approximately one-fifth of the patients receiving NOAC treatment had bleeding events. Despite the follow-up period of 3 months, major $(4.9 \%)$ and minor (16\%) bleeding was higher than our data. This difference might be related to the lower mean HAS-BLED score of the patients who participated in our study $(2 \pm 1.2$ versus $3 \pm 1$, respectively).

The major and minor clinically relevant bleeding has been shown to occur in $1.9 \%$ and $12.9 \%$ patients, respectively, in the 


\begin{tabular}{|c|c|c|c|c|c|c|c|c|}
\hline Sites of minor bleeding & $\begin{array}{c}\text { Dabigatran } \\
150 \mathrm{mg} \\
(\mathrm{n}=273)\end{array}$ & $\begin{array}{c}\text { Dabigatran } \\
110 \mathrm{mg} \\
(\mathrm{n}=409)\end{array}$ & $\begin{array}{c}\text { Rivaroxaban } \\
20 \mathrm{mg} \\
(\mathrm{n}=385)\end{array}$ & $\begin{array}{c}\text { Rivaroxaban } \\
15 \mathrm{mg} \\
(\mathrm{n}=276)\end{array}$ & $\begin{array}{c}\text { Apixaban } \\
5 \mathrm{mg} \\
(\mathrm{n}=308)\end{array}$ & $\begin{array}{c}\text { Apixaban } \\
2.5 \mathrm{mg} \\
(\mathrm{n}=156)\end{array}$ & $\begin{array}{c}\text { Total } \\
(\mathrm{n}=1.807)\end{array}$ & $P$ \\
\hline GIS, n (\%) & $5(1.8)$ & $12(2.9)$ & $8(2.1)$ & $9(3.3)$ & $4(1.3)$ & $2(1.3)$ & $40(2.2)$ & 0.320 \\
\hline Epistaxis, n (\%) & $6(2.2)$ & $7(1.7)$ & $2(0.5)$ & $2(0.7)$ & $2(0.6)$ & $2(1.3)$ & $21(1.2)$ & 0.495 \\
\hline Hematuria, n (\%) & $2(0.7)$ & $3(0.7)$ & $5(1.3)$ & $2(0.7)$ & $5(1.6)$ & $6(3.8)$ & $23(1.3)$ & 0.700 \\
\hline Hemoptysis, n (\%) & $1(0.4)$ & $0(0)$ & $0(0)$ & $0(0)$ & $0(0)$ & $0(0)$ & $1(0.1)$ & 0.533 \\
\hline Bruising/ecchymosis, $\mathrm{n}(\%)$ & $1(0.4)$ & $0(0)$ & $1(0.3)$ & $0(0)$ & $0(0)$ & $0(0)$ & $2(0.1)$ & 0.896 \\
\hline Urinary system/vaginal, n (\%) & $0(0)$ & $1(0.2)$ & $1(0.3)$ & $0(0)$ & $1(0.3)$ & $0(0)$ & $3(0.2)$ & 0.999 \\
\hline Intramuscular, $\mathrm{n}(\%)$ & $0(0)$ & $0(0)$ & $0(0)$ & $0(0)$ & $0(0)$ & $1(0.6)$ & $1(0.1)$ & 0.900 \\
\hline Conjunctival, n (\%) & $2(0.7)$ & $3(0.7)$ & $8(2.1)$ & $0(0)$ & $1(0.3)$ & $1(0.6)$ & $15(0.8)$ & 0.081 \\
\hline Intra-articular, n (\%) & $0(0)$ & $2(0.5)$ & $1(0.3)$ & $1(0.4)$ & $0(0)$ & $0(0)$ & $4(0.2)$ & 0.449 \\
\hline Retroperitoneal, n (\%) & $1(0.4)$ & $2(0.5)$ & $1(0.3)$ & $2(0.7)$ & $0(0)$ & $0(0)$ & $6(0.3)$ & 0.881 \\
\hline Gingival bleeding, $\mathrm{n}(\%)$ & $12(4.4)$ & $11(2.7)$ & $13(3.4)$ & $9(3.3)$ & $0(0)$ & $0(0)$ & $45(2.5)$ & 0.744 \\
\hline \multicolumn{9}{|l|}{ Sites of major bleeding } \\
\hline GIS, n (\%) & $1(0.4)$ & $10(2.4)$ & $2(0.5)$ & $1(0.4)$ & $1(0.3)$ & $2(1.3)$ & $17(0.9)$ & 0.289 \\
\hline Epistaxis, n (\%) & $0(0)$ & $0(0)$ & $1(0.3)$ & $1(0.4)$ & $1(0.3)$ & $0(0)$ & $3(0.2)$ & 0.990 \\
\hline Hematuria, n (\%) & $0(0)$ & $0(0)$ & $0(0)$ & $3(1.1)$ & $1(0.3)$ & $0(0)$ & $4(0.2)$ & 0.970 \\
\hline Hemoptysis, n (\%) & $0(0)$ & $0(0)$ & $0(0)$ & $2(0.7)$ & $0(0)$ & $0(0)$ & $2(0.1)$ & 0.977 \\
\hline Bruising/ecchymosis, n (\%) & $1(0.4)$ & $0(0)$ & $0(0)$ & $1(0.4)$ & $0(0)$ & $1(0.6)$ & $3(0.2)$ & 0.999 \\
\hline Urinary system/vaginal, n (\%) & $0(0)$ & $1(0.2)$ & $0(0)$ & $0(0)$ & $0(0)$ & $0(0)$ & $1(0.1)$ & 0.982 \\
\hline Intramuscular, $\mathrm{n}(\%)$ & $0(0)$ & $0(0)$ & $1(0.3)$ & $0(0)$ & $0(0)$ & $0(0)$ & $1(0.1)$ & 0.989 \\
\hline Intracranial, n (\%) & $0(0)$ & $2(0.5)$ & $0(0)$ & $2(0.7)$ & $1(0.3)$ & $1(0.6)$ & $6(0.3)$ & 0.992 \\
\hline \multicolumn{9}{|l|}{ Management of bleeding } \\
\hline $\begin{array}{l}\text { Medical or surgical } \\
\text { intervention }\end{array}$ & $18(56.3)$ & $36(63.2)$ & $32(69.6)$ & $27(77.1)$ & $12(70.6)$ & $15(83.3)$ & $140(68.3)$ & 0.300 \\
\hline Hospitalization & $11(34.4)$ & $26(45.6)$ & $15(32.6)$ & $18(51.4)$ & $9(52.9)$ & $12(66.7)$ & $91(44.4)$ & 0.120 \\
\hline Temporary discontinuation & $14(43.8)$ & $26(45.6)$ & $29(63)$ & $21(60)$ & $10(58.8)$ & $14(77.8)$ & $113(55.1)$ & 0.119 \\
\hline $\begin{array}{l}\text { Change in antithrombotic } \\
\text { therapy }\end{array}$ & $13(40.6)$ & $22(38.6)$ & $14(30.4)$ & $11(31.4)$ & $9(52.9)$ & $6(33.3)$ & $75(36.6)$ & 0.634 \\
\hline
\end{tabular}

rivaroxaban study; the results were in line with our study (24). The major bleeding and total bleeding rates with dabigatran $110 \mathrm{mg}$ bid were $2.71 \%$ and $14.62 \%$, respectively, per year in the RE-LY study (3). Both these rates have been reported to increase to $3.11 \%$ and $16.42 \%$, respectively, per year with dabigatran $150 \mathrm{mg}$ bid. However, in our study, patients receiving dabigatran $110 \mathrm{mg}$ bid $(13.9 \%)$ had more total bleeding events than those who received dabigatran $150 \mathrm{mg}$ bid $(11.7 \%)$. In addition, patients in our study who received dabigatran $150 \mathrm{mg}$ bid were younger (median age: 68.7 versus 76.5 years), had a lower HAS-BLED score (1.9 versus $2.2)$, and better renal functions (3.3\% versus $10.3 \%)$. In addition, there was no intracranial bleeding with dabigatran $150 \mathrm{mg}$, which was not observed in the Spanish cohort either (25).

In a previous study, rivaroxaban $15 \mathrm{mg}$ was associated with higher major bleeding events than rivaroxaban $20 \mathrm{mg}(2.2 \%$ and
$1.5 \%$, respectively) (26). Furthermore, Huang et al. (27) have also reported that rivaroxaban $15 \mathrm{mg}$ was related to a higher number of intracranial bleeding and GIS bleeding events than rivaroxaban $20 \mathrm{mg}$. Therefore, this current study showed that a reduced dose of DOACs was associated with higher bleeding events. Our data are similar with previous studies $(22,26,27)$. This paradox may be associated with group variation. In this study, the treatment dosage might have been determined by physicians on the basis of their judgment in the clinical setting. Hence, patients in the high dose DOACs group tended to be less fragile and had a lower risk of bleeding as indicated by lower HAS-BLED scores. However, patients taking high doses were older, more fragile, had poor renal function, and higher CHA2DS2-VASc, HAS-BLED, and ATRIA scores.

In this study, we showed that bleeding events were lower than those in some previous pilot studies. This difference might 
be explained by the lower HAS-BLED score, younger age, and higher GFR (3-5). During our study, the physicians likely had concerns about bleeding in patients treated by DOAC; therefore, they may have chosen patients with lower HAS-BLED scores and a lower ratio of patients with renal impairment for treatment. However, our results are similar to those of the Spanish cohort that investigated the effectiveness and safety of treatment of DOAC in daily practice (25).

In this study, $15(66.7 \%)$ patients taking apixaban $(2.5 \mathrm{mg})$ bid were hospitalized. This could be explained by the fragility of these patients owing to age and high morbidity. In the ARISTOTLE study, patients presenting with minor bleeding were slightly more likely to require medical or surgical consultations (78.8\%) compared with those treated with warfarin $(70.1 \%)$. This study had similar results; $15(83.3 \%)$ patients on apixaban $(2.5 \mathrm{mg})$ required medical or surgical consultation. However, hospitalizations were higher in our study than in previous studies $(66.7 \%$ versus $12.9 \%)(28)$. The mean age of patients on apixaban in the ARISTOTLE study was 70 years, whereas in this study, it was 81.6 years. The high rate of hospitalization might be explained by the older and more fragile patient population. Furthermore, 118 patients on apixaban $(2.5 \mathrm{mg})$ were hospitalized in the ARISTOTLE study; however, only 12 patients were hospitalized in this study because our number of patients on apixaban $(2.5 \mathrm{mg})$ and other DOACs were less than those in the previous pilot studies (28). This finding could also be a result of concern about the use of DOAC and a lack of knowledge about the options for the management of DOAC-related bleeding. Bleeding management and outcomes were evaluated and compared with those of the RE-LY study. The number of medical or surgical interventions, hospitalizations, temporary discontinuities, and change in antithrombotic therapy was higher in this study than in previous studies. This difference could be explained by the easy access to healthcare and health policy of the region as well as the geographic properties and difficulties in transportation. This study was a real-life follow-up study and consisted of unselected patients.

We demonstrated that a total bleeding event occurred most often in the GIS tract (GIST) and was more frequent with rivaroxaban and dabigatran than apixaban. This was followed by bleeding in the urinary tract and skin without any significant statistical difference. However, major bleeding in the GIST was the most frequent in patients [10 (2.4\%)] receiving dabigatran 110 $\mathrm{mg}$ bid. In the RE-LY study, dabigatran $150 \mathrm{mg}$ bid increased the relative risk of major GIST bleeding. However, patients receiving dabigatran $110 \mathrm{mg}$ bid had lower GIST bleeding. Dabigatran was the first DOAC in Turkey, and the side effect of GIST is well known. Therefore, dabigatran $110 \mathrm{mg}$ bid might be given to patients with the disease and symptoms of GIST. Patients receiving dabigatran $150 \mathrm{mg}$ bid also had a lower bleeding risk score, age, and renal impairment, although a recent systematic review and meta-analysis have demonstrated that there was no difference between the types of DOAC (29). The Spanish cohort (25) had similar results as our study, and other previous studies also have described similar bleeding locations.
Although minor bleeding from the gingival appeared to be more common with DOAC in our study, we could not obtain sufficient information on gingival bleeding with DOACs. However, we believe it could be related to periodontal health.

The main objective of this study was to analyze the safety of DOAC in clinical practice in Turkey. It has shown fewer bleeding events than in previous pilot studies, which might be explained by lower HAS-BLED $(2.0 \pm 1.2)$ and ATRIA $(4.8 \pm 4.3)$ scores. There was also a lower CRF [167 (9.2\%)] count and a shorter follow-up period.

We determined the risk factors using multiple Cox regression analyses for bleeding; rivaroxaban $20 \mathrm{mg}$ od, PAD, ATRIA, and HAS-BLED were the independent indicators of bleeding. PAD was associated with bleeding in this study. The EUCLID study showed that the bleeding events of patients with PAD treated with antiplatelet agents were higher than those without PAD (30). Moreover, the first step of NOAC-TURK study demonstrated higher bleeding events in patients with PAD (8). Overall, these results might be associated with patients with PAD who are older and have more severe disease. Future studies of patients with PAD should investigate this association in detail.

In this study, we found that rivaroxaban $20 \mathrm{mg}$ was an independent risk factor for bleeding (HR=1.760, 95\% Cl: 1.228-2.524, $\mathrm{p}=0.002$ ). These data are consistent with the results of the previous real-life data that showed that rivaroxaban $20 \mathrm{mg}$ is associated with a higher bleeding risk than other DOACs $(31,32)$. Furthermore, in the ROCKET-AF trial, the rates of bleeding events were similar for rivaroxaban and warfarin (4). The Spanish cohort also demonstrated that rates of major bleeding were slightly higher with rivaroxaban.

\section{Study limitations}

Unfortunately, we could not reach some of the participants from the first step of the NOAC-TURK study. The bias introduced could not be completely avoided. The DOAC medication prescribed was dependent on the time the drug was introduced into the market and its reimbursement; thus, edoxaban could not be included in the study. In this study, we could not obtain the data about the use of nonsteroidal anti-inflammatory drugs because our participants may have taken them without a prescription. Therefore, this might have affected the HAS-BLED score. The possible difference among the types of DOACs in the occurrence of intracranial bleeding could not be clearly elucidated because of the low number of intracranial bleeding events. Finally, we could not collect the data on the management of bleeding because of the insufficiency of the national health record system. The discontinuation was reported as temporary owing to not obtaining the exact number of permanent discontinuation from all centers.

\section{Conclusion}

This prospective study looked at a large cohort of patients with NVAF and reflects the results obtained using DOACs in a clinical practice in Turkey. The major and intracranial bleeding 
were similar for different DOACs. Rivaroxaban $20 \mathrm{mg}$ od was an independent indicator of bleeding, and reduced dosage of DOACs is associated with higher bleeding rates. The GIST and gingiva were the most common sites for major and minor bleeding, respectively.

\section{Conflict of interest: None declared.}

\section{Peer-review: Externally peer-reviewed.}

Author contributions: Concept - Ö.G., S.A., M.Ş., S.P.; Design - Ö.G., S.A., M.Ş., S.P.; Supervision - Ö.G., H.A.Ç., L.A., U.C., M.Ş., S.P.; Fundings - F.B., Ü.Y.S., U.C.; Materials - H.A.Ç., A.Y., F.B., Ü.Y.S., U.C.; Data collection \&/or processing - Ö.G., S.A., S.Ü., H.A.Ç., L.A., A.Y., F.B., Ü.Y.S., U.C.; Analysis \&/or interpretation - Ö.G., S.Ü., L.A., A.Y.; Literature search Ö.G., S.A., S.Ü., S.P.; Writing - Ö.G., S.Ü.; Critical review - Ö.G., S.Ü., H.A.C.., L.A., A.Y., F.B., Ü.Y.S., U.C.

\section{References}

1. Chugh SS, Havmoeller R, Narayanan K, Singh D, Rienstra M, Benjamin EJ, et al. Worldwide epidemiology of atrial fibrillation: a Global Burden of Disease 2010 Study. Circulation 2014; 129: 837-47. [Crossref]

2. Kirchhof $P$, Benussi S, Kotecha D, Ahlsson A, Atar D, Casadei B, et al.; ESC Scientific Document Group. 2016 ESC Guidelines for the management of atrial fibrillation developed in collaboration with EACTS. Eur Heart J 2016; 37: 2893-962. [Crossref]

3. Connolly SJ, Ezekowitz MD, Yusuf S, Eikelboom J, Oldgren J, Parekh A, et al.; RE-LY Steering Committee and Investigators. Dabigatran versus warfarin in patients with atrial fibrillation. $\mathrm{N}$ Engl $\mathrm{J}$ Med 2009; 361: 1139-51. [Crossref]

4. Patel MR, Mahaffey KW, Garg J, Pan G, Singer DE, Hacke W, et al.; ROCKET AF Investigators. Rivaroxaban versus warfarin in nonvalvular atrial fibrillation. N Engl J Med 2011; 365: 883-91. [Crossref]

5. Granger CB, Alexander JH, McMurray JJ, Lopes RD, Hylek EM, Hanna $M$, et al.; ARISTOTLE Committees and Investigators. Apixaban versus warfarin in patients with atrial fibrillation. $N$ Engl J Med 2011; 365: 981-92. [Crossref]

6. Eikelboom J, Merli G. Bleeding with Direct Oral Anticoagulants vs Warfarin: Clinical Experience. Am J Med 2016; 129 (11S): S33-40. [Crossref]

7. Nieuwlaat R, Capucci A, Lip GY, Olsson SB, Prins MH, Nieman FH, et al.; Euro Heart Survey Investigators. Antithrombotic treatment in real-life atrial fibrillation patients: a report from the Euro Heart Survey on Atrial Fibrillation. Eur Heart J 2006; 27: 3018-26. [Crossref]

8. Altay S, Yıldırımtürk Ö, Çakmak HA, Aşkın L, Sinan ÜY, Beşli F, et al.; NOAC-TURK Study Collaborators. New oral anticoagulants-TURKey (NOAC-TURK): Multicenter cross-sectional study. Anatol J Cardiol 2017; 17: 353-61. [Crossref]

9. Başaran Ö, Beton O, Doğan V, Tekinalp M, Aykan AÇ, Kalaycıoğlu E, et al.; RAMSES Study. ReAl-life Multicenter Survey Evaluating Stroke prevention strategies in non-valvular atrial fibrillation (RAMSES study). Anatol J Cardiol 2016; 16: 734-41. [Crossref]

10. Ertaş F, Kaya H, Yüksel M, Soydinç MS, Alan S, Ülgen MS. Atrial Fibrillation in Turkey: Epidemiologic Registry (AFTER) study design. Anatol J Cardiol 2013; 13: 339-43. [Crossref]
11. Emren SV, Şenöz O, Bilgin M, Beton O, Aslan A, Taşkin U, et al. Drug Adherence in Patients With Nonvalvular Atrial Fibrillation Taking Non-Vitamin K Antagonist Oral Anticoagulants in Turkey: NOAC-TR. Clin Appl Thromb Hemost 2018; 24: 525-31. [Crossref]

12. EINSTEIN Investigators, Bauersachs $R$, Berkowitz SD, Brenner B, Buller HR, Decousus H, Gallus AS, et al. Oral rivaroxaban for symptomatic venous thromboembolism. N Engl J Med 2010; 363: 2499510. [Crossref]

13. Lip GY, Nieuwlaat R, Pisters R, Lane DA, Crijns HJ. Refining clinical risk stratification for predicting stroke and thromboembolism in atrial fibrillation using a novel risk factor-based approach: the euro heart survey on atrial fibrillation. Chest 2010; 137: 263-72. [Crossref]

14. Pisters R, Lane DA, Nieuwlaat R, de Vos CB, Crijns HJ, Lip GY. A novel user-friendly score (HAS-BLED) to assess 1-year risk of major bleeding in patients with atrial fibrillation: the Euro Heart Survey. Chest 2010; 138: 1093-100. [Crossref]

15. Fang MC, Go AS, Chang Y, Borowsky LH, Pomernacki NK, Udaltsova $\mathrm{N}$, et al. A new risk scheme to predict warfarin-associated hemorrhage: The ATRIA (Anticoagulation and Risk Factors in Atrial Fibrillation) Study. J Am Coll Cardiol 2011; 58: 395-401. [Crossref]

16. Levey AS, Bosch JP, Lewis JB, Greene T, Rogers N, Roth D. A more accurate method to estimate glomerular filtration rate from serum creatinine: a new prediction equation. Modification of Diet in Renal Disease Study Group. Ann Intern Med 1999; 130: 461-70. [Crossref]

17. Schulman S, Kearon C. Subcommittee on Control of Anticoagulation of the Scientific and Standardization Committee of the International Society on Thombosis and Haemostasis. Definition of major bleeding in clinical investigations of antihemostatic medicinal products in non-surgical patients. J Thromb Haemost 2005; 3: 692-4. [Crossref]

18. Sørensen R, Gislason G, Torp-Pedersen C, Olesen JB, Fosbøl EL, Hvidtfeldt MW, et al. Dabigatran use in Danish atrial fibrillation patients in 2011: a nationwide study. BMJ Open 2013; 3: e002758. [Crossref]

19. Nielsen PB, Skjøth F, Søgaard M, Kjældgaard JN, Lip GY, Larsen TB. Effectiveness and safety of reduced dose non-vitamin $\mathrm{K}$ antagonist oral anticoagulants and warfarin in patients with atrial fibrillation: propensity weighted nationwide cohort study. BMJ 2017; 356: j510. [Crossref]

20. Königsbrügge 0 , Simon A, Domanovits $H$, Pabinger I, Ay C. Thromboembolic events, bleeding, and drug discontinuation in patients with atrial fibrillation on anticoagulation: a prospective hospital-based registry. BMC Cardiovasc Disord 2016; 16: 254. [Crossref]

21. Halvorsen S, Ghanima W, Fride Tvete I, Hoxmark C, Falck P, Solli O, et al. A nationwide registry study to compare bleeding rates in patients with atrial fibrillation being prescribed oral anticoagulants. Eur Heart J Cardiovasc Pharmacother 2017; 3: 28-36. [Crossref]

22. Lip GY, Laroche C, Dan GA, Santini M, Kalarus Z, Rasmussen LH, et al. A prospective survey in European Society of Cardiology member countries of atrial fibrillation management: baseline results of EURObservational Research Programme Atrial Fibrillation (EORPAF) Pilot General Registry. Europace 2014; 16: 308-19. [Crossref]

23. Helmert S, Marten S, Mizera H, Reitter A, Sahin K, Tittl L, et al. Effectiveness and safety of apixaban therapy in daily-care patients with atrial fibrillation: results from the Dresden NOAC Registry. J Thromb Thrombolysis 2017; 44: 169-78. [Crossref] 
24. Camm AJ, Amarenco P, Haas S, Hess S, Kirchhof P, Kuhls S, et al.; XANTUS Investigators. XANTUS: a real-world, prospective, observational study of patients treated with rivaroxaban for stroke prevention in atrial fibrillation. Eur Heart J 2016; 37: 114553. [Crossref]

25. Navarro-Almenzar B, Cerezo-Manchado JJ, Caro-Martinez C, García-Candel F, Flores Blanco PJ, Ruiz GE, et al. Real-life behaviour of direct oral anticoagulants in a Spanish cohort with nonvalvular atrial fibrillation: Refase Registry. Curr Med Res Opin 2019; 35: 2035-41. [Crossref]

26. Blin P, Fauchier L, Dureau-Pournin C, Sacher F, Dallongeville J, Bernard MA, et al. Effectiveness and Safety of Rivaroxaban 15 or $20 \mathrm{mg}$ Versus Vitamin $\mathrm{K}$ Antagonists in Nonvalvular Atrial Fibrillation. Stroke 2019; 50: 2469-76. [Crossref]

27. Huang HY, Lin SY, Cheng SH, Wang CC. Effectiveness and Safety of Different Rivaroxaban Dosage Regimens in Patients with NonValvular Atrial Fibrillation: A Nationwide, Population-Based Cohort Study. Sci Rep 2018; 8: 3451. [Crossref]
28. Bahit MC, Lopes RD, Wojdyla DM, Held C, Hanna M, Vinereanu D, et al. Non-major bleeding with apixaban versus warfarin in patients with atrial fibrillation. Heart 2017; 103: 623-8. [Crossref]

29. Laine L. Bleeding With Direct Oral Anticoagulants: The Gastrointestinal Tract and Beyond. Clin Gastroenterol Hepatol 2017; 15: 1665-7. [Crossref]

30. Ward R, Huang Z, Rockhold FW, Baumgartner I, Berger JS, Blomster $\mathrm{JI}$, et al. Major bleeding in patients with peripheral artery disease: Insights from the EUCLID trial. Am Heart J 2020; 220: 51-8. [Crossref]

31. Deitelzweig S, Farmer C, Luo X, Li X, Vo L, Mardekian J, et al. Comparison of major bleeding risk in patients with non-valvular atrial fibrillation receiving direct oral anticoagulants in the realworld setting: a network meta-analysis. Curr Med Res Opin 2018; 34: 487-98. [Crossref]

32. Larsen TB, Skjøth F, Nielsen PB, Kjældgaard JN, Lip GY. Comparative effectiveness and safety of non-vitamin $\mathrm{K}$ antagonist oral anticoagulants and warfarin in patients with atrial fibrillation: propensity weighted nationwide cohort study. BMJ 2016; 353: i3189. [Crossref] 